\title{
RANCANG BANGUN SISTEM INFORMASI PELAYANAN JASA BUBUT PADA UTAMA TEKNIK BERBASIS WEB
}

\author{
Yunita ${ }^{1}$, Raditya Ramadhan Al Riyadi ${ }^{2}$, Hilda Amalia ${ }^{3}$ \\ 1,2,3 Universitas Bina Sarana Informatika \\ e-mail: 1yunita.ynt@bsi.ac.id, ${ }^{2}$ radit080712@gmail.com, ${ }^{3}$ hilda.ham@bsi.ac.id
}

\begin{abstract}
Abstraksi
Perkembangan dunia industri mengalami peningkatan yang sangat signifikan, berimbas pada permintaan akan sparepart dan jasa bubut. tetapi di zaman yang sudah terkomputerisasi ini tidak semua tempat jasa pelayanan bengkel bubut mengikuti perkembangan teknologi. Utama Tehnik salah satunya, merupakan perusahaan yang bergerak dibidang jasa bubut atau pembuatan spare part otomotif maupun fabrikasi. Hingga saat ini Utama Tehnik ini melakukan pelayanan kepada konsumen dengan sistem manual. Oleh karna itu timbulah permasalahan pelayanan seperti catatan pemesanan berceceran, nota pembayaran hilang, tidak adanya evaluasi pendapatan. Dengan demikian, perlu menerapkan penggunaan aplikasi agar dapat mendukung segala bentuk pencatatan, pembayaran maupun pembuatan laporan agar pelayanan jasa bubut bisa tersimpan dengan cepat, tepat dan akurat. Untuk membangun sebuah system informasi dibutuhkan sebuah model, model air terjun yang sederhana cocok digunakan untuk mengembangkan perangkat lunak. Apakah efektivitas air terjun dalam merancang system dapat menyederhanakan pekerjaan dibidang pelayanan jasa bubut.
\end{abstract}

Kata Kunci : sistem Informasi, jasa bubut, air terjun

\begin{abstract}
The development of the industrial world experienced a very significant increase, impacting the demand for spare parts and lathe services. but in this computerized era, not all of the garage service centers follow technological developments. Main Technics, one of which, is a company engaged in lathe services or manufacturing automotive and fabrication spare parts. Until now the Main Technique is providing services to consumers with a manual system. Therefore, service problems arise, such as scattered booking records, payment receipts are lost, there is no evaluation of income. Thus, it is necessary to apply the use of applications in order to support all forms of recording, payment and reporting so that the lathe services can be stored quickly, accurately and accurately. To build an information system a model is needed, a simple waterfall model is suitable for developing software. Is the effectiveness of the waterfall in designing the system can simplify the work in the field of lathe services.
\end{abstract}

Keywords: information system, lathe service, waterfall

\section{Pendahuluan}

Perkembangan dunia industri mengalami peningkatan yang sangat signifikan, berimbas pada permintaan akan sparepart dan jasa bubut. Tuntutan akan berbagai informasi yang cepat dan akurat sangatlah berpengaruh dalam dunia bisnis (Febrianto \& Handayani, 2019). Akan tetapi di zaman yang sudah terkomputerisasi ini tidak semua tempat jasa pelayanan bengkel bubut mengikuti perkembangan teknologi.

Utama Tehnik salah satunya, merupakan perusahaan yang bergerak dibidang jasa bubut atau pembuatan spare part otomotif maupun fabrikasi. Hingga saat ini Utama Tehnik ini melakukan pelayanan kepada konsumen dengan sistem manual yaitu mencatat pemesanan dengan media kertas, mencatat pembayaran dengan nota, tidak adanya pembuatan laporan dan melakukan promosi dengan cara konvensional yaitu menunggu pembeli dan dari mulut kemulut. Oleh karna itu timbulah permasalahan pelayanan seperti catatan pemesanan berceceran, nota pembayaran hilang, tidak adanya evaluasi pendapatan dan juga tidak adanya media promosi melalui internet.

Menurut Ramanda dalam (Rusman \& Angraini, 2019) Sistem informasi sangat bisa dihandalkan untuk memecahkan berbagai masalah yang terjadi pada seseorang maupun perusahaan yang 
bergerak di bidang barang maupun jasa. Dimana Sistem informasi menjadi alat bantu yang efektif untuk melayani permintaan data. Dalam meningkatkan kinerjanya, suatu perusahaan dapat memanfaatkan ilmu pengetahuan dan teknologi informasi sebagai sarana pengolahan data secara cepat, tepat dan akurat. Perlu suatu terobosan pelayanan maupun promosi dalam penyampaian informasi.

Diperlukan sebuah desain sistem informasi pengolahan data dan sarana promosi pada bengkel (Febrianto \& Handayani, 2019). Dengan demikian, perlu menerapkan penggunaan aplikasi agar dapat mendukung segala bentuk pencatatan, pembayaran maupun pembuatan laporan agar pelayanan jasa bubut bisa tersimpan dengan cepat, tepat dan akurat. Berdasarkan latar belakang yang telah dikemukakan di atas, maka perumusan masalah yang telah diteliti adalah apakah efektivitas model waterfall dalam membangun system pelayanan jasa bubut dapat mempermudah pekerjaan dibidang pelayanan jasa bubut.

\section{Metode Penelitian}

Untuk menghasilkan suatu system yang baik didalam system informasi pelayanan jasa bubut, diperlukan tahapan penelitian, yang disajikan pada Gambar 1 :

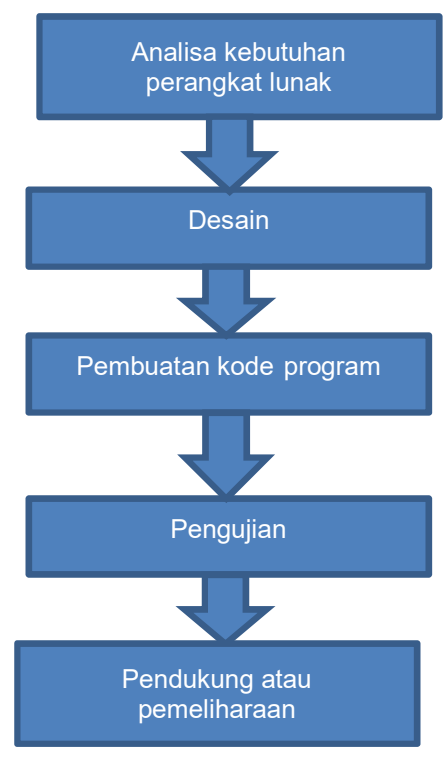

Sumber : penulis (2020) Gambar 1 Tahapan penelitian
Pada gambar 5 disajikan tahapan peneliltian yang ditempuh melalui lima langkah (A.S \& Shalahuddin, 2014). Tahapan pertama adalah analisa kebutuhan perangkat lunak. Dalam analisa kebutuhan perangkat lunak dilakukan beberapa cara. Teknik pertama adalah dilakukan Tanya jawab atau wawancara. Wawancara dilakukan oleh orang-orang yang terlibat langsung dengan sistem pelayanan jasa bubut. Dari teknik wawancara diperoleh masalah yang dihadapi oleh badan usaha serta mendapatkan gambaran mengenai sistem informasi yang akan dibangun. Teknik berikutnya adalah dilakukan pengumpulan data dengan cara observasi yaitu dilakukan pengamatan langsung di tempat proses pelayanan jasa. Sehingga diperoleh datadata yang dibutuhkan untuk membangun sistem yang dapat menyelesaikan masalah pada bidang pelayanan jasa. Dari obsevasi diperoleh mengenai gambaran sistem yang berjalan, analisa dilakukan dengan melakukan analisa dokumen. Tahapan kedua yakni Desain, dalam tahapan ini dilakukan design sistem dengan menggunakan diagram UML(Unifed Modelling Language), design table dengan ERD(Entity Relationship Diagram). Tahapan ketiga yaitu pembuatan coding program dengan menggunakan bahasa pemograman web yaitu bahasa pemograman php serta memanfaatkan bahasa Mysql. Tahapan keempat adalah pengujian, dalam tahapan ini dilakukan uji coba sistem yang sudah ditelah dibuat dengan menggunakan blackbox testing. Black box testing dilakukan untuk memastikan keluaran sistem sesuai dengan yang diinginkan

\section{Hasil dan Pembahasan}

Hasil dan pembahasan didalam rancang bangun system informasi pelayanan jasa bubut berdasarkan tahapan penelitian akan dijabarkan sebagai berikut : 3.1. Analisa Kebutuhan Perangkat Lunak A. Analisa Kebutuhan system

Kebutuhan system merupakan layanan dalam sebuah aplikasi yang harus disediakan, serta gambaran proses dari reaksi system terhadap masukan system (Nurfarida, Amalia, \& Yunita, 2020)

1. Skenario Kebutuhan Konsumen

a. Melihat Informasi website ( Home, Layanan, Profil, Login, Keranjang, Riwayat Pesanan, Logout, Checkout ) Utama Tehnik 
b. Mendaftar sebagai user

c. Melakukan pemesanan jasa

2. Skenario Kebutuhan Admin

a. Memproses data pemesanan jasa yang masuk

b. Mengupload design gambar

c. Mencetak bukti pemesanan

d. Mengelola data layanan, data konsumen, data bahan dan data user

3. Skenario Kebutuhan Operator

a. Memproses pengerjaan pesanan sesuai arahan dan design gambar dari admin

b. Mengubah status pemesanan

4. Skenario Kebutuhan Owner

a. Melihat laporan transaksi

B. Kebutuhan Sistem

1. Pengguna harus melakukan login terlebih dahulu untuk dapat mengakses sistem berbasis web ini, dengan memasukan username untuk login user (konsumen) lalu username khusus yang diberikan oleh admin untuk owner dan operator, disertakan dengan memasukan password agar privasi masing - masing pengguna tetap terjaga

2. Sistem meyimpan seluruh history pemesanan user (konsumen) pada masing - masing akun user yang melakukan pemesanan jasa apabila proses pemesanan jasa telah selesai dilakukan

3. Seluruh pengguna harus melakukan logout apabila telah selesai menggunakan website

\subsection{Desain}

3.2.1. Rancangan Diagram Use Case

A. Diagram Use Case Pelayanan Jasa

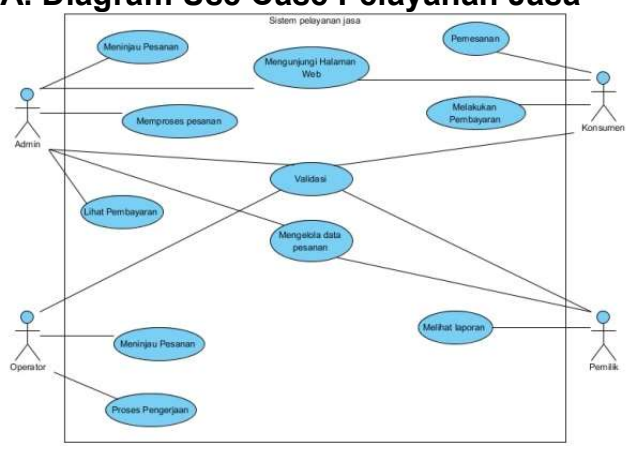

Sumber : penulis (2020)
Gambar 2 Diagram Use Case Pelayanan Jasa

B. Diagram Use Case Pendaftaran

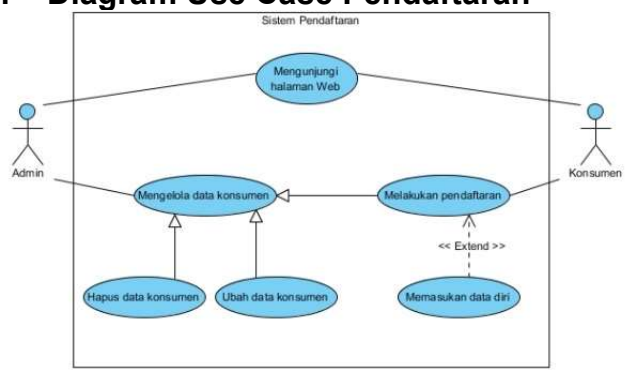

Sumber : penulis (2020)

Gambar 3 Diagram Use Case

Pendaftaran

C. Diagram Use Case Pemesanan

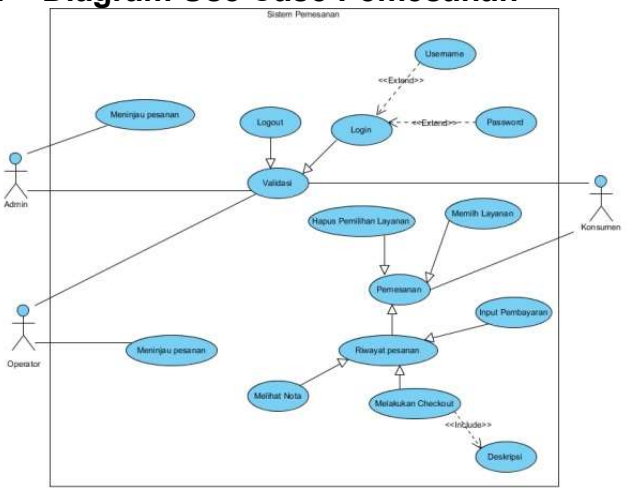

Sumber : penulis (2020)

Gambar 4 Diagram Use Case

Pemesanan 


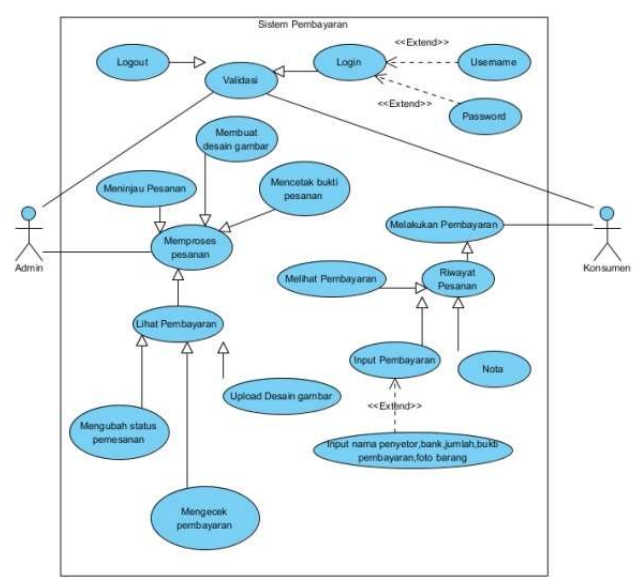

Sumber : penulis (2020)

Gambar 5 Diagram Use Case

Pembayaran

\section{E. Diagram Use Case Pengerjaan}

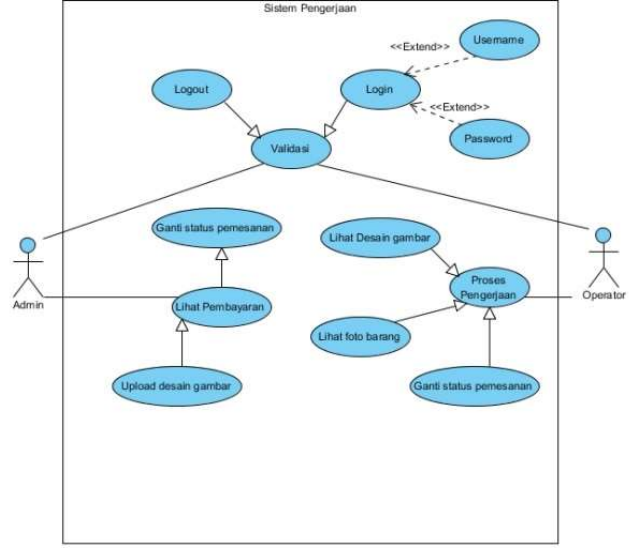

Sumber : penulis (2020)

Gambar 6 Diagram Use Case Pengerjaan

\section{F. Diagram Use Case Laporan}

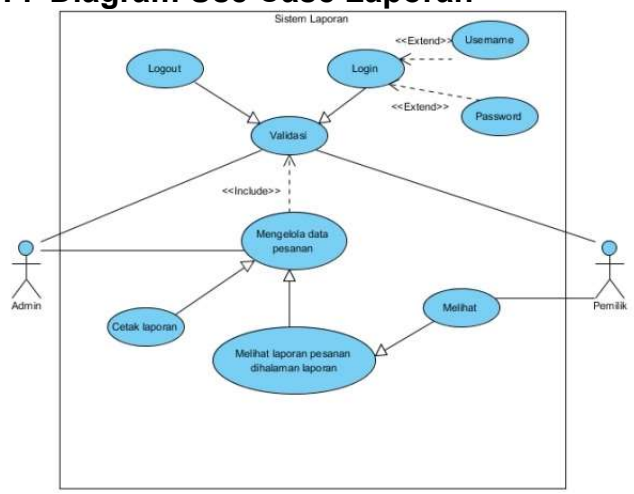

Sumber : penulis (2020)

Gambar 7 Diagram Use Case Laporan
A. Diagram Aktivitas Pendaftaran

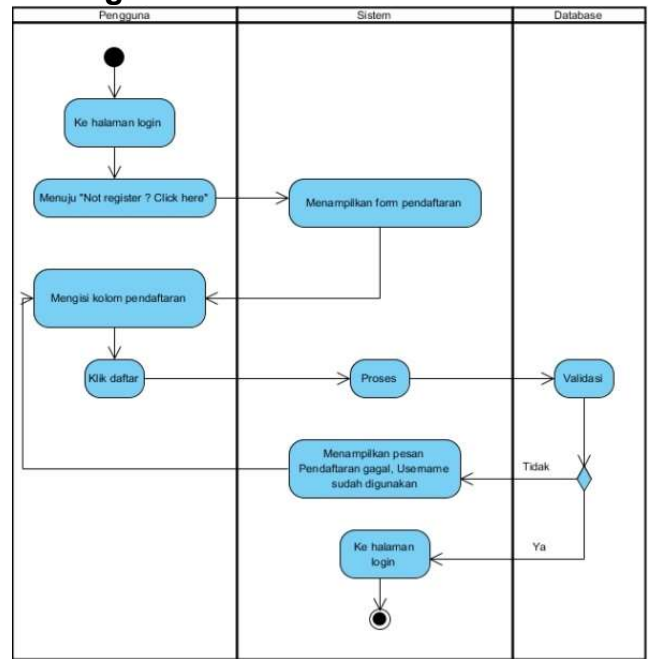

Sumber : penulis (2020)

Gambar 7 Diagram Aktivitas Pendaftaran

B. Diagram Aktivitas Login

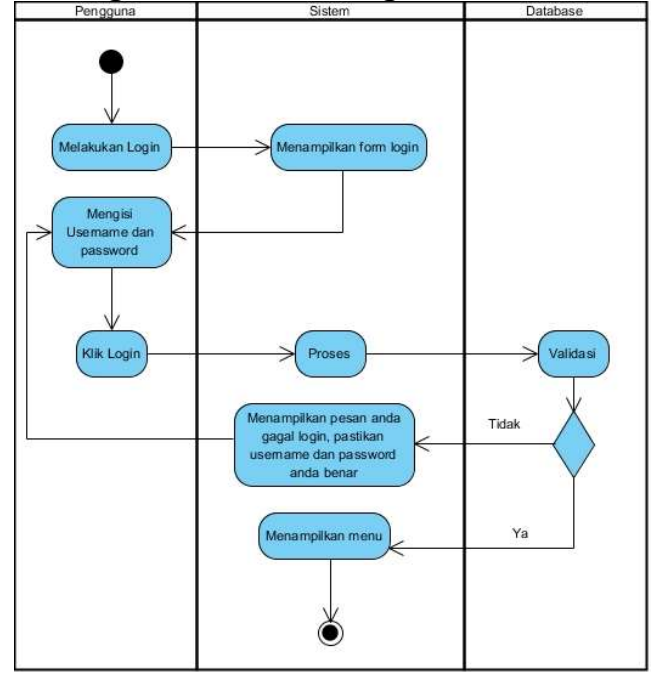

Sumber : penulis (2020)

Gambar 7 Diagram Aktivitas login

\subsubsection{Rancangan Diagram Aktivitas}




\section{Diagram Aktivitas Pelayanan Jasa}

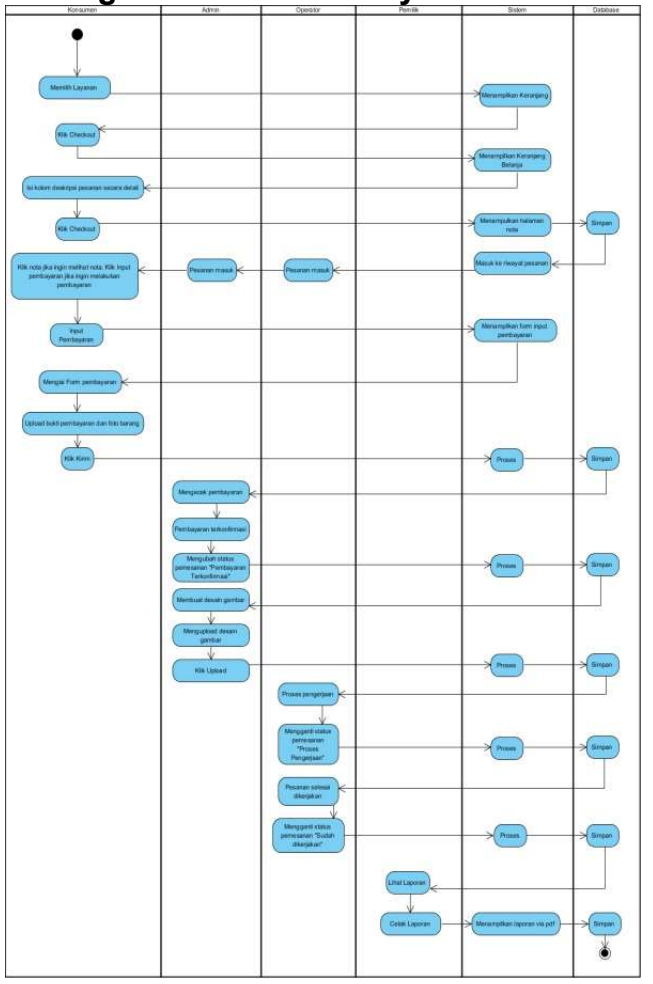

Sumber : penulis (2020)

Gambar 9 Diagram Aktivitas Pelayanan jasa

\subsubsection{Entity Relational Diagram (ERD)}

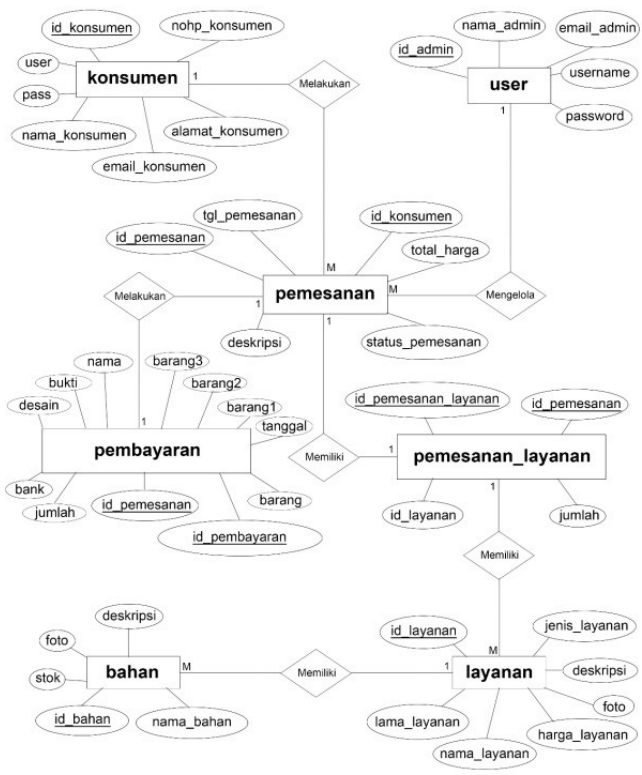

Sumber : penulis (2020)

Gambar 10 ERD

\subsubsection{Logical Record Structure (LRS)}

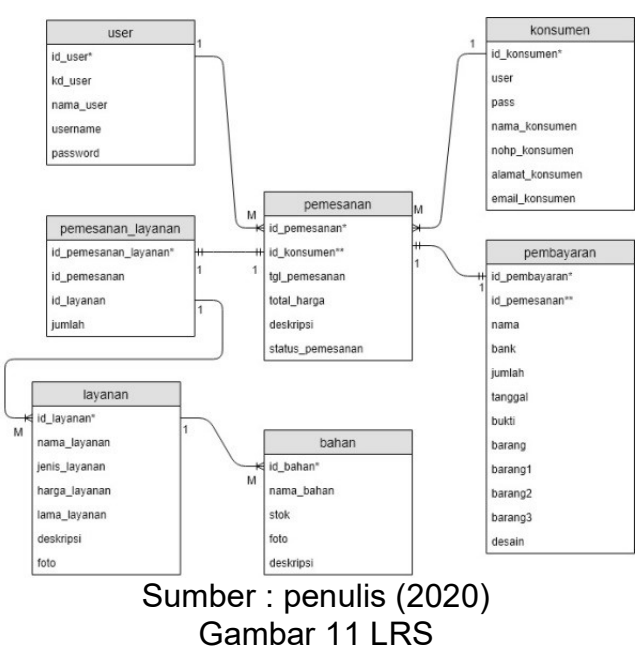

3.2.5. Rancangan Class Diagram

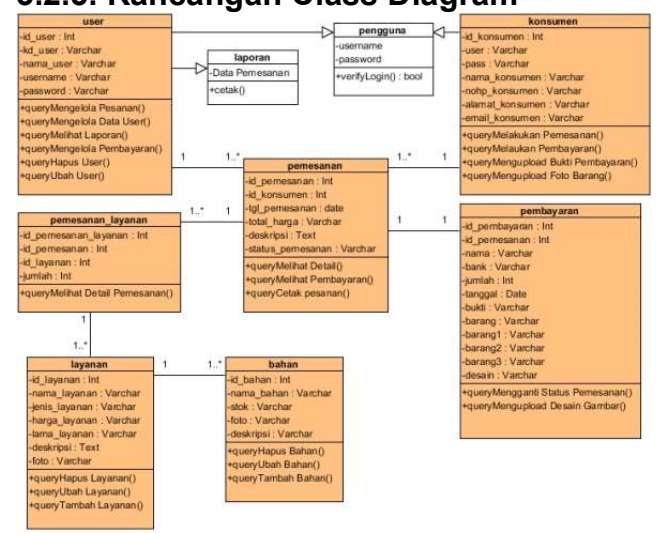

Sumber : penulis (2020)

Gambar 11 Class Diagram

\subsection{Pembuatan Kode Program}

Hasil dalam tahapan ini adalah program computer yang sesuai dengan desain yang telah dibuat pada tahap desain (Yunita \& Jamal, 2019). Untuk pelayanan jasa ini menggunakan script php dan aplikasi dreamweaver 8 .

\subsection{Pengujian}

Pengujian rancang bangun system pelayanan jasa bubut pada Utama Teknik menggunakan metode blackbox testing.

Tabel 1 Pengujian Form Login Admin

\begin{tabular}{|c|c|c|c|c|c|}
\hline $\begin{array}{l}\mathrm{N} \\
\mathrm{O}\end{array}$ & $\begin{array}{l}\text { Skenario } \\
\text { Pengujian }\end{array}$ & $\begin{array}{l}\text { Test } \\
\text { Case }\end{array}$ & $\begin{array}{c}\text { Hasil } \\
\text { yang } \\
\text { diharapk } \\
\text { an }\end{array}$ & $\begin{array}{c}\text { Hasil } \\
\text { Pengu } \\
\text { jian }\end{array}$ & $\begin{array}{c}\text { Ketera } \\
\text { ngan }\end{array}$ \\
\hline 1 & $\begin{array}{l}\text { Mengoso } \\
\text { ngkan } \\
\text { data } \\
\text { username } \\
\text { dan } \\
\text { password } \\
\text { lalu klik } \\
\text { 'Login' }\end{array}$ & $\begin{array}{l}\text { Usern } \\
\text { ame: } \\
\text { (koson } \\
\text { g) } \\
\text { Passw } \\
\text { ord: } \\
\text { (koson } \\
\text { g) }\end{array}$ & $\begin{array}{l}\text { Sistem } \\
\text { akan } \\
\text { menolak } \\
\text { akses } \\
\text { login } \\
\text { dan } \\
\text { akan } \\
\text { muncul }\end{array}$ & $\begin{array}{l}\text { Sesua } \\
\text { i } \\
\text { harap } \\
\text { an }\end{array}$ & Valid \\
\hline
\end{tabular}




\begin{tabular}{|c|c|c|c|c|c|}
\hline & & & $\begin{array}{l}\text { dialog } \\
\text { "Isi isian } \\
\text { ini" }\end{array}$ & & \\
\hline 2 & $\begin{array}{l}\text { Mengoso } \\
\text { ngkan } \\
\text { data } \\
\text { username } \\
\text { dan } \\
\text { mengisi } \\
\text { data } \\
\text { password } \\
\text { 'Llalu klik } \\
\text { 'Login' }\end{array}$ & $\begin{array}{l}\text { Usern } \\
\text { ame: } \\
\text { (koson } \\
\text { g) } \\
\text { Passw } \\
\text { ord: } \\
\text { (isi }\end{array}$ & $\begin{array}{l}\text { Sistem } \\
\text { akan } \\
\text { menolak } \\
\text { akses } \\
\text { login } \\
\text { dan } \\
\text { akan } \\
\text { muncul } \\
\text { dialog } \\
\text { "Isi isian } \\
\text { ini" }\end{array}$ & $\begin{array}{l}\text { Sesua } \\
\text { i } \\
\text { harap } \\
\text { an }\end{array}$ & Valid \\
\hline 3 & $\begin{array}{l}\text { Mengisi } \\
\text { data } \\
\text { username } \\
\text { benar } \\
\text { password } \\
\text { salah, lalu } \\
\text { klik } \\
\text { 'Login' }\end{array}$ & $\begin{array}{l}\text { Usern } \\
\text { ame: } \\
\text { (benar } \\
\text { ) } \\
\text { Passw } \\
\text { ord: } \\
\text { (salah) }\end{array}$ & $\begin{array}{l}\text { Sistem } \\
\text { akan } \\
\text { menolak } \\
\text { akses } \\
\text { login } \\
\text { dan } \\
\text { akan } \\
\text { muncul } \\
\text { dialog } \\
\text { "Userna } \\
\text { me Atau } \\
\text { Passwor } \\
\text { d Salah" }\end{array}$ & $\begin{array}{l}\text { Sesua } \\
\mathrm{i} \\
\text { harap } \\
\text { an }\end{array}$ & Valid \\
\hline 4 & $\begin{array}{l}\text { Mengisi } \\
\text { data } \\
\text { username } \\
\text { salah } \\
\text { password } \\
\text { benar, } \\
\text { lalu klik } \\
\text { 'Login' }\end{array}$ & $\begin{array}{l}\text { Usern } \\
\text { ame: } \\
\text { (salah) } \\
\text { Passw } \\
\text { ord: } \\
\text { (benar } \\
\text { ) }\end{array}$ & $\begin{array}{l}\text { Sistem } \\
\text { akan } \\
\text { menolak } \\
\text { akses } \\
\text { login } \\
\text { dan } \\
\text { akan } \\
\text { muncul } \\
\text { dialog } \\
\text { "Userna } \\
\text { me Atau } \\
\text { Passwor } \\
\text { d Salah" }\end{array}$ & $\begin{array}{l}\text { Sesua } \\
\text { i } \\
\text { harap } \\
\text { an }\end{array}$ & Valid \\
\hline 5 & $\begin{array}{l}\text { Mengisi } \\
\text { data } \\
\text { Usernam } \\
\text { e dan } \\
\text { Password } \\
\text { dengan } \\
\text { benar, } \\
\text { lalu klik } \\
\text { 'Login' }\end{array}$ & $\begin{array}{l}\text { Usern } \\
\text { ame: } \\
\text { (Isi) } \\
\text { Passw } \\
\text { ord: } \\
\text { (Isi) }\end{array}$ & $\begin{array}{l}\text { Sistem } \\
\text { akan } \\
\text { meneri } \\
\text { ma } \\
\text { akses } \\
\text { login } \\
\text { dan } \\
\text { menam } \\
\text { pilkan } \\
\text { halaman } \\
\text { Beranda }\end{array}$ & $\begin{array}{l}\text { Sesua } \\
\text { i } \\
\text { harap } \\
\text { an }\end{array}$ & Valid \\
\hline
\end{tabular}

Sumebr : penulis (2020)

\subsection{Implementasi}

\section{A. Halaman Login Admin}
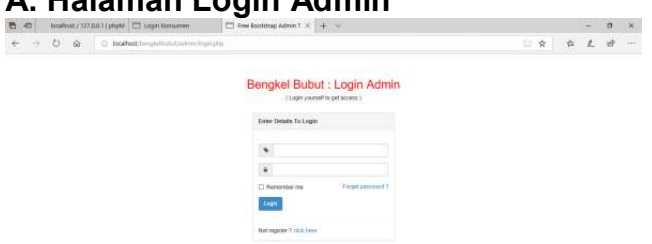

Sumber : penulis (2020)

Gambar 12 Halaman Login Admin

\section{B. Halaman Menu Utama Admin}

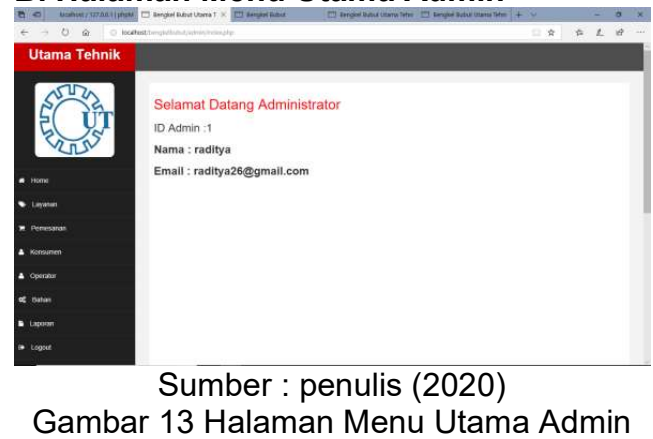

\section{Halaman Layanan}

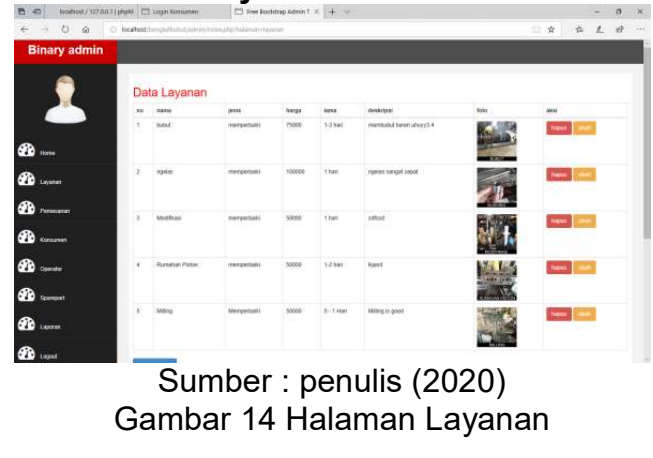

\section{Halaman Pemesanan}

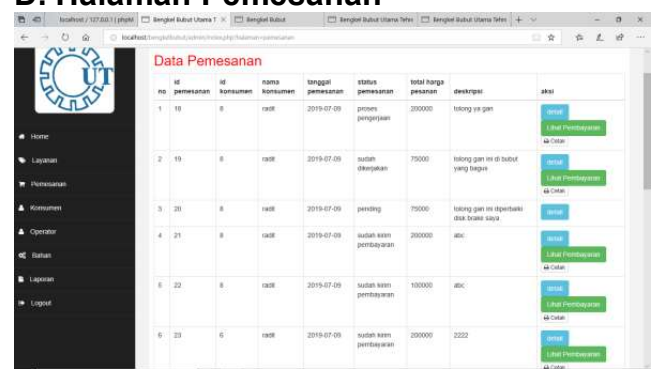

Sumber : penulis (2020)

Gambar 15 Halaman Pesanan

\section{E. Halaman Pembayaran}

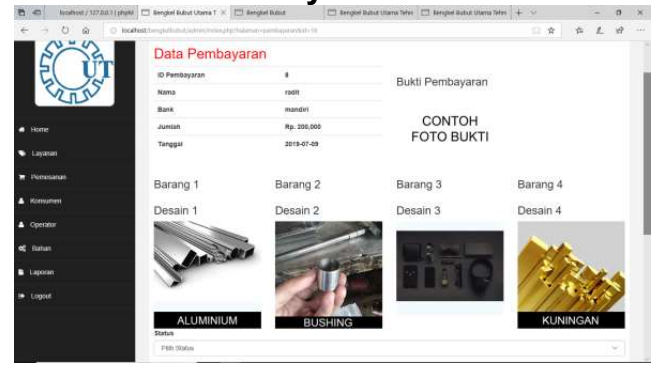

Sumber : penulis (2020)

Gambar 16 Halaman Pembayaran 


\section{F. Halaman Konsumen}

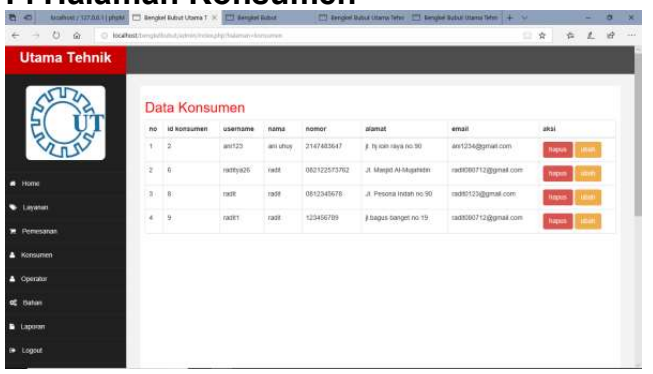

Sumber : penulis (2020)

Gambar 17 Halaman Konsumen

G. Halaman User

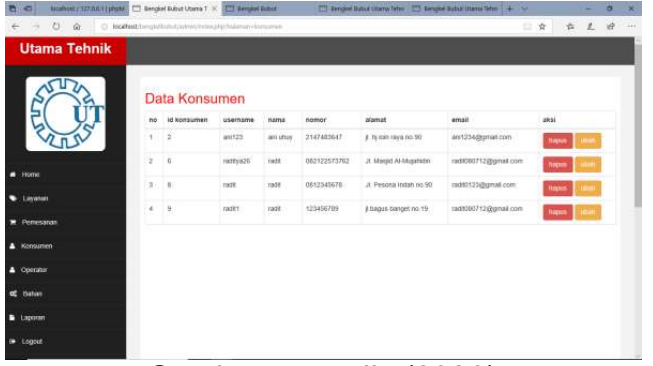

Sumber : penulis (2020)

Gambar 18 Halaman User

\section{H. Halaman Bahan}

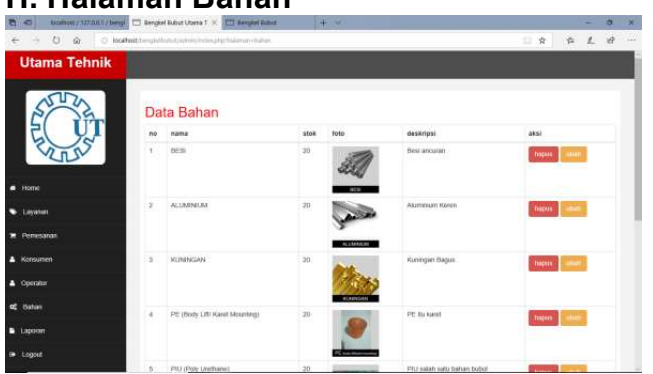

Sumber : penulis (2020)

Gambar 19 Halaman Bahan

\section{Halaman Laporan}

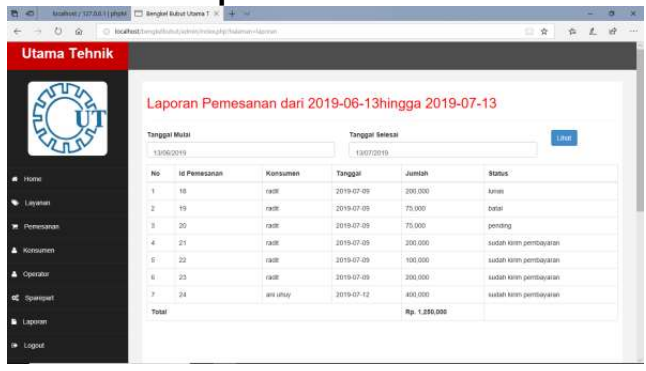

Sumber : penulis (2020)Gambar 20 Halaman Laporan

\section{Kesimpulan}

Penelitian yang telah dilakukan dan diuraikan menghasilkan beberapa kesimpulan yaitu : Sistem informasi pelayanan jasa bubut telah melalui tahapan pengujian dan sesuai dengan harapan kebutuhan pengguna. System yang sebelumnya masih bersifat manual dan menyebabkan terjadi beberapa permasalahan dengan adanya system ini dapat menghilangkan terjadinya kesalahan, pembuatan desain yang masih manual sekarang dikerjakan dengan system yang sudah terkomputerisasi begitupun dengan prosedur pemesanan, pembayaran sampai dengan pembuatan laporan, sehingga meningkatkan efektivitas pelayanan jasa dan dapat mempermudah konsumen dalam memesan jasa pembuatan bubut. Dengan system yang dibangun dapat mengubah kinerja dari Bengkel Utama Teknik menjadi lebih baik dan professional.

\section{Referensi}

A.S, R., \& Shalahuddin, M. (2014). Rekayasa Perangkat Lunak. Informatika. Bandung.

Febrianto, A., \& Handayani, P. (2019). Rancang Bangun Sistem Pelayanan Jasa Bubut Berbasis Web Pada CV. Sukses Abadi Jaya Tangerang, XXI(1), 17-22. https://doi.org/10.31294/p.v20i2

Nurfarida, Amalia, H., \& Yunita, Y. (2020). Rancang Bangun Sistem Informasi Biaya Perjalanan Dinas. Jurnal Teknik Komputer, VI(1), 19-30.

Rusman, A., \& Angraini, S. L. (2019). Penerapan Extreme Programming Pada Sistem Informasi Pembayaran Sumbangan Pembinaan Pendidikan ( SPP ), $\quad X X I(1), \quad 17-22$. https://doi.org/10.31294/p.v20i2

Yunita, Y., \& Jamal, A. M. (2019). Rancang Bangun Sistem Informasi Pemesanan Rumah Pada Pt. Graha Bakti Semesta. Swabumi, 7(2), 166-171. https://doi.org/10.31294/swabumi.v7i2 .6625 